\title{
Medical schools can cooperate: a new joint venture to provide medical education in the Northern Rivers region of New South Wales
}

\author{
Sue L Page, Hudson H Birden, J Nicky Hudson, Jill E Thistlethwaite, Chris Roberts, lan Wilson, \\ John Bushnell, John Hogg, S Ben Freedman and Neville Yeomans
}

A ustralia currently has a medical workforce situation which, if unchecked, will see a deepening of the serious shortage of doctors in rural communities. Achieving sustainability in the supply of doctors to rural and regional areas is therefore one of the biggest challenges facing all medical schools, as well as state and federal governments. ${ }^{1}$

The traditional interaction between medical schools has been competitive, not collaborative, and accounts of joint educational ventures between them are uncommon. ${ }^{2-7}$ However, there are a number of Commonwealth-funded collaborative initiatives underway in regional and rural Australia to address the rural workforce gap. These include the Joint Medical Program of the University of Newcastle, the University of New England, and Hunter New England Health; ${ }^{6}$ the Northern Victoria Regional Medical Education Network, formed in 2006 by the University of Melbourne and Monash University; ${ }^{8}$ and a collaboration between the University of Western Australia and the University of Notre Dame, which has given rise to the Rural Clinical School of Western Australia. ${ }^{9}$

Continuing in the spirit of these programs, the nation's newest medical schools, at the University of Western Sydney (UWS) and the University of Wollongong (UoW), have formed a partnership with the oldest, at the University of Sydney (USyd), to develop a joint program in regional and rural medical education. The initiative stemmed from the desire of doctors working in the Northern Rivers region and the Northern Rivers University Department of Rural Health (NRUDRH) to establish their own identity as a new rural clinical training site. The NRUDRH, while part of USyd's Faculty of Medicine, already provided short-term placements for students from 14 other universities in nine disciplines, so it seemed sensible to make this a shared resource. After first approaching the Australian Government Department of Health and Ageing for conceptual guidance and to explore potential funding opportunities, discussion with UoW and UWS in early 2005 resulted in an innovative new partnership - the North Coast Medical Education Collaboration (NCMEC) (Box 1).

\section{The educational program}

The NCMEC is developing a shared program for the education of medical students in regional and rural settings on the New South Wales North Coast, similar in concept to the distributed education model adopted by medical schools in North America, ${ }^{10}$ where rural doctor shortages are comparable to those in Australia.

All medical students will be offered elective clinical placements of up to 40 weeks ( 1 academic year) at NCMEC sites on the North Coast in one of their final two years (ie, third-year and fourth-year students from UoW and USyd, and fourth-year and fifth-year students from UWS; Box 2). An integrated placement is a requirement of the UoW program. NCMEC placements will be of interest to students planning any generalist or specialist career.

\section{ABSTRACT}

- The medical schools at the University of Western Sydney, University of Wollongong and University of Sydney have developed a joint program for training medical students through placements of up to 40 weeks on the New South Wales North Coast.

- The new partnership agency - the North Coast Medical Education Collaboration - builds on the experience of regional doctors and their academic partners.

- A steering committee has identified the availability and support requirements of local practitioners to provide training, and has undertaken a comparative mapping of learning objectives and assessments from the courses of the three universities.

- The goals of the program include preparing doctors who can perform effectively in rural settings and multidisciplinary health care teams, and to advance research in medical education.

MJA 2008; 188: 179-181

During their North Coast clinical experience, students will gain an understanding of medicine and medical practice in regional and rural communities, including Indigenous health, ${ }^{11}$ through working in a larger shared working environment than would be possible in a single school. Assessable learning outcomes will be the same as for fellow students in metropolitan and other placements. The program builds on the experience of North Coast regional doctors, the health provider system, and their academic partners in providing short-term rural placements.

In the spirit of collaboration, each of the partner universities shared their vision of medical education and the learning outcomes of their medical course. A comparative mapping of learning objectives from the curricula of the three universities was devel-

1 Innovative aspects of the North Coast Medical Education Collaboration program

- Is a cooperative venture between two new medical schools and one long-established medical school

- Offers year-long rural placements

- Provides interdisciplinary education in teams of health care students and practitioners

- Agreement between the medical schools on shared formative assessment

- Students from the three medical schools share accommodation and social experiences 


\section{MEDICAL EDUCATION}

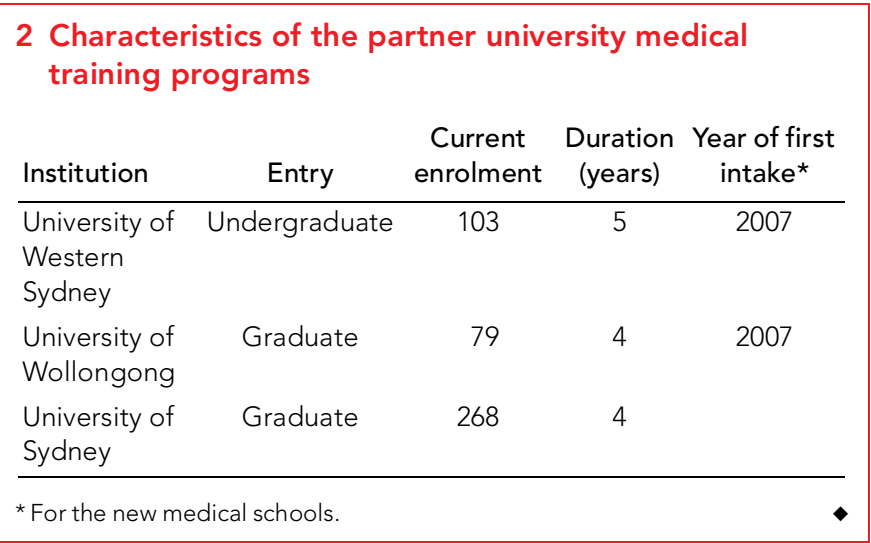

oped, and confirmed that there is a high degree of congruence between them. Using the results of this mapping exercise, clinical competence and personal and professional behaviour assessments will be linked to common learning outcomes. While the patientoriented clinical encounter is a major focus of education in all three programs, the roles of the multidisciplinary team in health promotion and chronic care will also receive special emphasis in the NCMEC program.

The NCMEC program design embraces the assimilation of clinical skills through an immersion experience in rural practice settings, and will also strive to build clinical leadership skills and foster the ability of doctors to work effectively in multidisciplinary health teams. The ongoing approach is to initially identify the overall desired outcomes from the educational experience and then to build specific learning activities to meet them. ${ }^{12}$ In the program's longitudinal community placement, it will be akin to the Flinders University Parallel Rural Community Curriculum. ${ }^{13}$ While the learning experience will be an integrated one, the curriculum is set by the individual partner universities, in keeping with Australian Medical Council requirements.

\section{Delivery and assessment}

Delivery of the shared educational program will rely heavily on local practitioners. Placements will be with a mix of rural general practitioners, rural hospitals, and local patient care services of other types, including mental health, community health, and population health centres. A steering committee has quantified the amount of time local clinicians have available to provide learning experiences for students, and how this will affect their practice, as well as what types of educational support and training clinicians will need; what clinical experiences are available that are not classified or scheduled as formal educational sessions; and what resources the NCMEC will need to deliver to support educational and assessment activity. Through this process, the steering committee has also identified additional support that the participating clinicians, especially GPs, will need. This includes logistics support from student coordinators for scheduling, reimbursement for teaching time, and teaching skill support and development.

The program will have a mix of shared assessments and specific assessments required by the individual school curricula. Major summative assessments and objective structured clinical examinations (OSCEs) will be conducted through the students' home schools. Mini-CEX (mini clinical evaluation exercise) will be the preferred mode of delivery for shared assessments. Professional personal development will be assessed by continual structured feedback by supervisors during placements and through reflective journal exercises.

In keeping with the philosophy that medical students should have a voice in the make-up of their educational program, ${ }^{12}$ the NCMEC will consider students to be professional partners. As such, they will be challenged to become involved in the planning of learning activities. Their longitudinal immersion in patient care settings will introduce students to the dilemmas and realities of the practice of medicine earlier and more directly than would the traditional tertiary hospital, specialty-based curriculum (although modern hospital-based curricula are starting to reflect these values as well). Students embedded in practice situations develop a sense of themselves as health professionals earlier than their counterparts trained in traditional hospital ward settings only. ${ }^{14,15}$

\section{Clinical placements}

Starting in 2007, some third-year and fourth-year USyd students have already begun 12-week clinical placements on the North Coast. Before commencing their rural community placements in 2009 (UoW) and 2010 (UWS), NCMEC students from these universities will have had earlier community-based experiences in various settings. All will have some preparatory knowledge on which to build a successful program of extended study. Indeed, UoW has already placed 20 first-year students at NCMEC sites for 3 weeks in June 2007 for an interdisciplinary team experience. These students were attached to chronic care teams in Indigenous health, mental health, child health, diabetes care, rehabilitation, and other disciplines. In undertaking these placements, the students have initiated a longitudinal connection with the North Coast in anticipation of their potential return to the region later in their training.

The ideas and experiences of both the USyd senior students and UoW first-year students on the North Coast over the next 2 years will contribute to the development of future integrated learning experiences for students from all three medical schools. This early test of the practicality of placing students in rotations convened and supervised by professionals from allied health, mental health, nursing, and other disciplines will serve as a model for future NCMEC endeavours to impart an ability to work in interdisciplinary teams. NCMEC students will also be integrated with students from other disciplines in problem-based learning sessions and tutorials.

There are several strengths that the NCMEC program will draw on to make rural medical education successful. One is the richness of resources that the three universities, combined with a thriving regional health care system noted for excellence in health service delivery, can contribute to supporting such a program. Another is the set of lessons already learned from other rural clinical placement programs, particularly those in Australia. ${ }^{13,16}$

The NCMEC program will be subject to robust evaluation. Data on satisfaction and performance of students, including participatory action research with students as co-researchers and a mixed qualitative and quantitative assessment of program components, will capture the lessons learned by the NCMEC for the wider medical education and health care community.

In being a joint venture of three medical schools, both old and new, NCMEC is unique. The goals of the program are ambitious the intent is to create a program innovative in the degree to which multidisciplinary health care and research in health care and 


\section{MEDICAL EDUCATION}

medical education are emphasised in rural placements. Three medical schools are cooperating; the outcome will depend on their success in focusing on the common aspects of their curricula and assessments, and their capacity to constructively engage with delivery of medical education through the rural health communities with which they work.

\section{Acknowledgements}

We gratefully acknowledge the support of the Australian Government Department of Health and Ageing.

\section{Competing interests}

None identified.

\section{Author details}

Sue L Page, BMed, FRACGP, FACRRM, Director ${ }^{1}$

Hudson H Birden, MPH, Senior Lecturer ${ }^{1}$

J Nicky Hudson, BM BS, MSc, PhD, Director of Clinical Education ${ }^{2}$

Jill E Thistlethwaite, MB BS, PhD, MMEd, Director, Research and

Teaching ${ }^{3}$

Chris Roberts, MB ChB, MMedSci, PhD, Director and Associate Dean ${ }^{3}$

Ian Wilson, MB BS, PhD, FRACGP, Professor of Medical Education ${ }^{4}$

John Bushnell, PhD, Deputy Dean ${ }^{2}$

John Hogg, MB BS, PhD, Foundation Dean²

S Ben Freedman, MB BS, BSc(Med), PhD, Associate Dean and Professor of Cardiology 5

Neville Yeomans, MB BS, MD, Dean ${ }^{4}$

1 North Coast Medical Education Collaboration, Lismore, NSW.

2 Graduate School of Medicine, University of Wollongong,

Wollongong, NSW.

3 Centre for Innovation in Professional Health Education and Research,

University of Sydney, Sydney, NSW.

4 School of Medicine, University of Western Sydney, Sydney, NSW.

5 Faculty of Medicine, University of Sydney, Sydney, NSW.

Correspondence: hudsonb@med.usyd.edu.au

\section{References}

1 Rourke J. Social accountability in theory and practice. Ann Fam Med 2006; 4 Suppl 1: S45-S48.
2 Stimmel B. The Mount Sinai School of Medicine Consortium for Graduate Medical Education: a collaboration to enhance quality. Mt Sinai J Med 2005; 72: 291-295.

3 Margolis CZ, Deckelbaum RJ, Henkin Y, et al. A medical school for international health run by international partners. Acad Med 2004; 79: 744-751.

4 van der Vleuten CP, Schuwirth LW, Muijtjens AM, et al. Cross institutional collaboration in assessment: a case on progress testing. Med Teach 2004; 26: 719-725

5 Schwarz MR. The WAMI Program: 25 years later. Med Teach 2004; 26: 211-214.

6 The Joint Medical Program. The University of Newcastle and University of New England. Executive summary 2007. http://www.amc.org.au/Newcastle.pdf (accessed Dec 2007).

7 Prideaux D, Teubner J, Sefton A, et al. The Consortium of Graduate Medical Schools in Australia: formal and informal collaboration in medical education. Med Educ 2000; 34: 449-454.

8 University of Melbourne. Melbourne/Monash network wins new rural med places. UniNews 2006; 15 (13). http://uninews.unimelb.edu.au/ articleid_3531.html (accessed May 2007).

9 Rural Clinical School of Western Australia [website]. http:// www.rcs.uwa.edu.au/go/rcs (accessed Dec 2007).

10 Bates J, Casiro O, Fleming B, et al. Expanding undergraduate medical education in British Columbia: a distributed campus model. CMAJ 2005; 173. Epub 2005 Sep 13. http://www.cmaj.ca/cgi/data/173/6/589/DC1/1 (accessed Mar 2007).

11 Phillips G; Project Steering Committee, Committee of Deans of Australian Medical Schools. CDAMS Indigenous Health Curriculum Framework. Melbourne: VicHealth Koori Health Research and Community Development Unit, 2004. http://www.medicaldeans.org.au/pdf/ CDAMS\%2OIndigenous\%20Health\%20Curriculum\%20Framework.pdf (accessed May 2007).

12 D'Eon M, Crawford R. The elusive content of the medical-school curriculum: a method to the madness. Med Teach 2005; 27: 699-703.

13 Worley P, Silagy C, Prideaux D, et al. The parallel rural community curriculum: an integrated clinical curriculum based in rural general practice. Med Educ 2000; 34: 558-565.

14 Maley MA, Denz-Penhey H, Lockyer-Stevens V, Murdoch JC. Tuning medical education for rural-ready practice: designing and resourcing optimally. Med Teach 2006; 28: 345-350.

15 Dornan T, Littlewood S, Margolis SA, et al. How can experience in clinical and community settings contribute to early medical education? A BEME systematic review. Med Teach 2006; 28: 3-18.

16 Hays R, Sen Gupta T. Ruralising medical curricula: the importance of context in problem design. Aust J Rural Health 2003; 11: 15-17.

(Received 18 Jun 2007, accepted 11 Sep 2007)

$\square$ 